University of Nebraska - Lincoln

DigitalCommons@University of Nebraska - Lincoln

Publications from USDA-ARS / UNL Faculty

U.S. Department of Agriculture: Agricultural

Research Service, Lincoln, Nebraska

3-24-2009

\title{
Molecular taxonomy, phylogeny and biogeography of nematodes belonging to the Trichinella genus
}

\author{
Edoardo Pozio \\ Istituto Superiore di Sanita, edoardo.pozio@iss.it \\ Eric Hoberg \\ United States Department of Agriculture \\ Giuseppe La Rosa \\ Istituto Superiore di Sanita
}

Dante S. Zarlenga

United States Department of Agriculture

Follow this and additional works at: https://digitalcommons.unl.edu/usdaarsfacpub

Pozio, Edoardo; Hoberg, Eric; Rosa, Giuseppe La; and Zarlenga, Dante S., "Molecular taxonomy, phylogeny and biogeography of nematodes belonging to the Trichinella genus" (2009). Publications from USDA-ARS / UNL Faculty. 2251.

https://digitalcommons.unl.edu/usdaarsfacpub/2251

This Article is brought to you for free and open access by the U.S. Department of Agriculture: Agricultural Research Service, Lincoln, Nebraska at DigitalCommons@University of Nebraska - Lincoln. It has been accepted for inclusion in Publications from USDA-ARS / UNL Faculty by an authorized administrator of DigitalCommons@University of Nebraska - Lincoln. 


\title{
Molecular taxonomy, phylogeny and biogeography of nematodes belonging to the Trichinella genus
}

\author{
Edoardo Pozio ${ }^{\mathrm{a}, *}$, Eric Hoberg ${ }^{\mathrm{b}}$, Giuseppe La Rosa ${ }^{\mathrm{a}}$, Dante S. Zarlenga ${ }^{\mathrm{b}}$ \\ ${ }^{a}$ Department of Infectious, Parasitic and Immunomediated Diseases, Istituto Superiore di Sanità, viale Regina Elena 299, 00161 Rome, Italy \\ ${ }^{\mathrm{b}}$ Animal Parasitic Diseases Laboratory, Agricultural Research Service, United States Department of Agriculture, Building 1180, BARC-East, Beltsville, MD 20705, USA
}

\section{A R T I C L E I N F O}

\section{Article history:}

Received 14 January 2009

Received in revised form 11 March 2009

Accepted 13 March 2009

Available online 24 March 2009

\section{Keywords:}

Trichinella

Nematodes

Molecular taxonomy

Phylogeny

Biogeography

Zoonosis

\begin{abstract}
A B S T R A C T
Studying parasites of the genus Trichinella provides scientists of today many advantages. This is a group of zoonotic nematodes that circulates freely among wildlife hosts with one in particular, Trichinella spiralis that is exceptionally well adapted to domestic swine. Recent reports suggest that human infections from hunted animals are on the rise worldwide and numerous countries still experience problems with $T$. spiralis in their domestic food supplies. Trichinella is a genus whose members are easily propagated in the laboratories, have been used as models to investigate host-parasite relationships and parasitism among clade I organisms, and represent a poorly investigated link between the phylum Nematoda and other Metazoans. The importance of T. spiralis in better understanding the tree of life was so recognized that in 2004 , its genome was carefully selected as one of only nine key non-mammalian organisms to be sequenced to completion. Since it was first discovered in 1835 , this genus has expanded from being monospecific to eight species including four other genotypes of undetermined taxonomic rank. Inasmuch as discriminating morphological data have been scant, our understanding of the genus has been relegated to a compilation of molecular, biochemical and biological data. Herein, we provide a collection of information and up-to-date interpretations on the taxonomy, diagnostics, systematics, micro- and macroevolution, and the biogeographical and biohistorical reconstruction of the genus Trichinella.
\end{abstract}

(c) 2009 Elsevier B.V. All rights reserved.

\section{Introduction}

Worms belonging to the genus Trichinella are unique among zoonotic nematodes. They are characterised by two generations in the same host and by infective first stage larvae (L1) rather than infective third stage larvae (L3) which typify most other nematode species (Pozio, 2007a). The only means of transmission is through the ingestion of infected, striated muscle tissue. The natural reservoirs of Trichinella species are wild carnivorous and omnivorous animals (Pozio, 2005). When humans fail to properly manage food animals or control the interface between wild and domestic animals, transmission of some species (i.e., Trichinella spiralis, $T$. britovi and T. pseudospiralis) can occur between these habitats. This transmission pattern inevitably involves pigs (Pozio and Murrell, 2006). Once an infection occurs in a population of domestic pigs, it can be perpetuated for many years within the neighbouring environment because of the scavenging and eating habits of these

\footnotetext{
* Corresponding author. Tel.: +3906 4990 2304; fax: +39 0649903561.

E-mail address: edoardo.pozio@iss.it (E. Pozio).
}

animals. This problem is exacerbated when scraps from "home slaughtered", infected pigs are scattered in local surroundings.

Trichinella parasites, which are widespread in all continents but Antarctica, are the etiological agents of a human disease, named trichinellosis (formerly known as trichiniasis or trichinosis), which can cause death in severe cases (Dupouy-Camet et al., 2002; Pozio and Murrell, 2006). If one considers all countries of the world, Trichinella spp. infections in domestic animals (mainly pigs) have been documented in $43(21.9 \%)$ countries, whereas infections in wildlife have been documented in 66 (33.3\%) countries (Pozio, 2007b). Human trichinellosis has been reported in 55 (27.8\%) countries worldwide; however, the presence of Trichinella in wild and/or domestic animals is not always linked to human infection. Eating habits of the hosts play important roles in transmission (Pozio, 2007b). Given the ability of this parasite to infect nearly all mammals, its cosmopolitan distribution, and its ability to appear in the domestic food supply, it is important to understand the many species that make up this genus. In addition, having an appreciation for the biogeography and species level diversity among these parasites will provide a foundation for more detailed studies of population structure relevant to patterns of geographic and host distribution, and the future threat of human trichinellosis. 


\section{Phylogeny and taxonomy}

\subsection{Trichinella and its historical context within Nematoda}

Recent history depicts the phylum Nematoda being separated into two classes, the Adenophorea and Secernentea predominantly based upon morphological and some molecular characters (Maggenti, 1983). Classically, the genus Trichinella has been grouped with the Adenophorea; however, more recent molecular data have begun to question this classification scheme (Blaxter et al., 1998). In 1998, Blaxter et al. re-evaluated hierarchical relationships among terrestrial and economically-important nematodes predicated on small subunit ribosomal DNA (ssu rDNA) sequence data. They concluded that the prior separation of Adenophorea and Secernentea was insufficiently descriptive and did not adequately represent the high frequency of homoplasy relative to parasitism and other independently evolved biological characters. The studies of Voronov et al. (1998) mirrored these findings where they reported distinct patterns of embryonic development that were in good agreement with the divisions proposed by Blaxter et al. (1998). In this classification scheme, the genus Trichinella was partitioned with clade I plant, insect, and marine parasites along with some freeliving nematodes. De Ley and Blaxter (2002) updated this phylogeny with morphological information to assist classification of organisms for which ssu rRNA information was not available. Holterman et al. (2006) performed more robust studies and concluded that the phylum would be best served if divided into 12 rather than five different clades as proposed by Blaxter et al. (1998). Most recently, Meldal et al. (2007) revised this phylogeny by including a large number of marine taxa that were severely underrepresented in previous analyses. They concluded that resolution at the base of the phylum was not sufficiently adequate to shed light on a marine ancestry for the group.

Data have recently surfaced suggesting that Trichinellidae and Trichuridae diverged from a common ancestor 250-300 million years ago (Ma) (Zarlenga et al., 2006). Estimates for the divergence of lineages leading to Caenorhabditis and Trichinella have been as high as $600 \mathrm{Ma}$ (Mitreva and Jasmer, 2006). Research performed by Parkinson et al. (2004) and more recently by Mitreva et al. (2004, $2005)$ indicated as much similarity (45-50\%) between $T$. spiralis (clade I) and Caenorhabditis elegans (clade V) as that shared between $T$. spiralis and the arthropod, Drosophila melanogaster based upon predicted consensus sequences from expressedsequence tag (EST) clusters. This level of similarity is more related to sequence conservation within the broader context of metazoan evolution but clearly demonstrates the great genetic diversity among organisms in the phylum Nematoda. This finding was mirrored in the mtDNA sequence of $T$. spiralis which in many aspects was more similar to non-nematode metazoans than to nematodes or was intermediate between these groups (Lavrov and Brown, 2001).

\subsection{Trichinella phylogeny and taxonomic structure: the earlier years}

For nearly 150 years following the 19 th century discovery of $T$. spiralis (Owen, 1835), the genus was considered to be monospecific (Table 1) (e.g., Pozio and Zarlenga, 2005). With the characterization of a handful of unique Trichinella isolates 30-35 years ago, the taxonomy of this genus became controversial (Pozio et al., 1992). Recent molecular epidemiological studies have served to validate the contributions of earlier work based on epidemiology (Rausch et al., 1956; Nelson, 1970; Rausch, 1970), cross-breeding (Britov and Boev, 1972), and biology and morphology (Garkavi, 1972). Thus, by the early 1970s, biological data had suggested that the genus comprised a complex of largely cryptic parasite species even though morphological characters among the group were equivocal (Lichtenfels et al., 1983). Indeed, the most telling character, the presence or absence of a host-derived, collagen sheath around the infected muscle cell led to the conclusion that the genus could be biologically delineated into 2 distinct groups: the encapsulated and nonencapsulated clades (Zarlenga et al., 2006). These groups received heightened interest from the genome sequencing community and in 2004, a major effort was launched to sequence the complete genome of $T$. spiralis as a representative clade 1 , encapsulated nematode (Mitreva and Jasmer, 2008). Genome sequencing efforts have since expanded to include the nonencapsulated species, T. pseudospiralis, using "next generation" sequencing technologies (Zarlenga et al., 2009) and T. spiralis data for comparative sequence assignment.

Better resolution of taxonomic issues has occurred only in the last 25 years, facilitated by the adoption of biochemical and molecular techniques (Flockhart et al., 1982; Mydynski and Dick, 1985; Fukumoto et al., 1987, 1988; Murrell et al., 1987; Pozio, 1987; La Rosa et al., 1992) which have been improved for both sensitivity and specificity (Chambers et al., 1986; Dame et al., 1987; Zarlenga and Barta, 1990; Zarlenga and Dame, 1992). Among the earliest dendrograms were those based upon distance algorithms of allozyme data from more than 150 field isolates obtained from different hosts and geographical origins (La Rosa et al., 1992). In their simplest forms, these trees biochemically delineated encapsulated and non-encapsulated species but broadly grouped the encapsulated genotypes with variable levels of resolution. Within this context, the allozyme data supported recognition of five species ( $T$. spiralis, T. nativa, $T$. britovi, $T$. pseudospiralis, and T. nelsoni) and three additional genotypes (Trichinella T5, T6, and T8) whose taxonomic rank was unresolved (La Rosa et al., 1992; Pozio et al., 1992). This proposal constitutes the current paradigm where modification has resulted only from the addition of new species and genotypes (Tables 1 and 2) (Pozio and Zarlenga, 2005; Krivokapich et al., 2008).

The use of polymerase chain reaction (PCR)-derived methods has been instrumental in identifying Trichinella isolates and has

Table 1

The taxonomy of the Trichinella genus from the parasite discovery to today.

\begin{tabular}{|c|c|c|c|}
\hline Year & Genus and species & Identification based on & Reference \\
\hline 1835 & Trichina spiralis & Morphology & Owen, 1835 \\
\hline 1892 & Trichinella spiralis & Not applicable & Railliet, 1896 \\
\hline 1972 & Trichinella nativa, T. nelsoni & Cross-breeding, epidemiology, zoogeography & Britov and Boev, 1972 \\
\hline 1972 & T. pseudospiralis & Biology, morphology & Garkavi, 1972 \\
\hline 1992 & $\begin{array}{l}\text { T. britovi, T. nelsoni s.s., } \\
\text { Trichinella T5, T6, and T8 }\end{array}$ & Allozymes, biology, epidemiology, zoogeography & Pozio et al., 1992 \\
\hline 1999 & T. papuae & Allozymes, molecular markers, biology, epidemiology, zoogeography & Pozio et al., 1999a \\
\hline 1999 & Trichinella T9 & Molecular markers & Nagano et al., 1999 \\
\hline 2000 & T. murrelli & Cross-breeding, biology, zoogeography & Pozio and La Rosa, 2000 \\
\hline 2002 & T. zimbabwensis & $\begin{array}{l}\text { Allozymes, molecular markers, biology, cross-Breeding, } \\
\text { epidemiology, zoogeography }\end{array}$ & Pozio et al., 2002 \\
\hline 2008 & Trichinella T12 & Molecular markers, epidemiology, zoogeography & Krivokapich et al., 2008 \\
\hline
\end{tabular}


Table 2

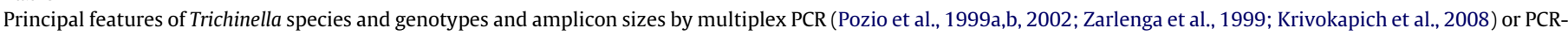
RFLP (Nagano et al., 1999).

\begin{tabular}{|c|c|c|c|c|c|}
\hline $\begin{array}{l}\text { Trichinella species } \\
\text { or genotype }\end{array}$ & Distribution & Cycle & Natural hosts & $\begin{array}{l}\text { Amplicon size by } \\
\text { multiplex PCR }\end{array}$ & $\begin{array}{l}\text { Amplicon size by } \\
\text { PCR-RFLP (Mse I) }\end{array}$ \\
\hline \multicolumn{6}{|l|}{ Encapsulated } \\
\hline T. spiralis & Cosmopolitan $^{a}$ & Domestic and sylvatic & Swine, rats, seldom carnivores & $173 \mathrm{bp}$ & $22,70,126,201 \mathrm{bp}$ \\
\hline T. nativa & $\begin{array}{l}\text { Arctic and subarctic areas of } \\
\text { Holoarctic region }^{\mathrm{b}}\end{array}$ & Sylvatic & Terrestrial and marine carnivores & $127 \mathrm{bp}$ & $22,70,327 \mathrm{bp}$ \\
\hline Trichinella T6 & Canada and United States & Sylvatic & Carnivores & $127,210 \mathrm{bp}$ & $22,70,327$ bp \\
\hline T. britovi & $\begin{array}{l}\text { Temperate areas of Palearctic } \\
\text { regionc, } \\
\text { northern and western Africa }\end{array}$ & Sylvatic, seldom domestic & Carnivores, seldom swine & $127,253 \mathrm{bp}$ & $22,62,64,70,201 \mathrm{bp}$ \\
\hline Trichinella T8 & South Africa and Namibia & Sylvatic & Carnivores & $127,253 \mathrm{bp}$ & $22,62,64,70,201 \mathrm{bp}$ \\
\hline T. murrelli & $\begin{array}{l}\text { Temperate areas of Nearctic } \\
\text { region }\end{array}$ & Sylvatic & Carnivores & $127,316 \mathrm{bp}$ & $92,126,201 \mathrm{bp}$ \\
\hline Trichinella T9 & Japan & Sylvatic & Carnivores & 127,253 bp & 92,327 bp \\
\hline T. nelsoni & Ethiopic region & Sylvatic & Carnivores, seldom swine & $127,404 \mathrm{bp}$ & $62,64,70,223$ bp \\
\hline Trichinella T12 & Argentina & Sylvatic & Carnivores & $127 \mathrm{bp}$ & unknown \\
\hline \multicolumn{6}{|l|}{ Non-encapsulated } \\
\hline T. pseudospiralis & Cosmopolitan & Sylvatic, seldom domestic & Mammals and birds & $310^{\mathrm{d}}, 340^{\mathrm{e}}, 360^{\mathrm{f}} \mathrm{bp}$ & 419 bp $^{\mathrm{d}}$ unknown ${ }^{\mathrm{e}, \mathrm{f}}$ \\
\hline T. papuae & Papua New Guinea, Thailand & Sylvatic, seldom domestic & Swine, saltwater crocodiles & 240 bp & Unknown \\
\hline T. zimbabwensis & $\begin{array}{l}\text { Ethiopia, Mozambique, } \\
\text { South Africa, Zimbabwe }\end{array}$ & Sylvatic and domestic & $\begin{array}{l}\text { Nile crocodiles, Nile monitor } \\
\text { lizards, lion }\end{array}$ & 264 bp & Unknown \\
\hline
\end{tabular}

a This species has not been detected in arctic regions.

b The isotherm $-4{ }^{\circ} \mathrm{C}$ in January is the southern limit of distribution.

c The isotherm $-6{ }^{\circ} \mathrm{C}$ in January is the northern limit of distribution.

d Palearctic region.

e Nearctic region.

${ }^{\mathrm{f}}$ Australian (Tasmania) region.

confirmed the taxonomy of the genus (Dick et al., 1992; Soule et al., 1993; Bandi et al., 1993, 1995; Wang et al., 1995; Gasser et al., 1998, 2004; Wu et al., 1998, 1999, 2000; Appleyard et al., 1999; Nagano et al., 1999; Zarlenga et al., 1999; Rombout et al., 2001; Pozio and La Rosa, 2003). Although PCR greatly advanced the identification of Trichinella species, its use in reconstructing the phylogeny was equivocal in earlier years. This lack of resolution was compounded by the use of random amplified polymorphic DNA (RAPD) data and inconsistencies in scoring the banding patterns. It became apparent that RAPD-based PCR profiles, and therefore the trees which resulted were often too subjective and heavily dependent upon the quality of the DNA. DNA integrity was frequently questionable when material was obtained from low numbers of parasites or from ethanol preserved specimens (Pozio et al., 1999b). By the late 1990s and the years that followed, the phylogeny became more solidified. Bandi et al. (1995), Zarlenga (1998) and La Rosa et al. (2003b) each used distinct methods to generate Unweighted Pair Group Method with Arithmetic mean (UPGMA)-based trees with better though not complete congruence. Discrepancies among the trees were rooted in the amount of sampling and in the characteristics of the different datasets. Nonetheless, certain incontrovertible facts became obvious; (1) both biological and genetic data partitioned the genus into two clades that coincided with capsule formation; (2) the nonencapsulated clade (e.g., T. pseudospiralis) was placed at the base of the tree, and; (3) the encapsulated clade was rooted with $T$. spiralis or $T$. nelsoni, relative to the freeze tolerant genotypes, $T$. nativa and Trichinella T6. Gasser et al. (2004) evaluated the genus using sequence information from the D3 domain of the nuclear ribosomal DNA which corroborated these conclusions but raised questions as to the relationships of $T$. britovi, T. murrelli and several other genotypes within the encapsulated clade, namely Trichinella T8 and T9. Later, van der Giessen et al. (2005) evaluated the 5S rRNA and came to similar conclusions; however, congruence among Palearctic and Nearctic genotypes remained equivocal and discrepancies continued over which species best rooted the encapsulated clade.

\subsection{Trichinella phylogeny and taxonomic structure: current dogma}

In 2006 and 2008, phylogenetic resolution using a multi-gene sequencing effort unequivocally established monophyly for the genus and validated eight nominal species and four species-level genotypes including the newly discovered, Trichinella T12 (Zarlenga et al., 2006; Krivokapich et al., 2008) (Fig. 1). On the basis of the variation in mitochondrial ( $\mathrm{mt}$ ) large subunit rRNA (lsu rRNA), the cytochrome c-oxidase subunit I (COI) DNA and rRNA internal transcribed sequences (ITS), two clades once again emerged coinciding with biological and isoenzyme data (See sections 2.1 and 2.2). Subsequent studies using a multi-gene analysis [5S intergeneric spacer region, lsu rDNA expansion segment V (ESV), and COI], corroborated this tree topology in the process of characterizing the new genotype, Trichinella T12 (Krivokapich et al., 2008). In both of these multi-gene analyses, $T$. spiralis was consistently placed as the basal taxon among the encapsulated forms. Among the non-encapsulated genotypes, those parasites infecting mammals and reptiles were partitioned from those infecting mammals and birds.

Molecular-based characterization resulting in accurate diagnostics, followed by phylogenetic resolution among the genotypes (Zarlenga et al., 2006; Krivokapich et al., 2008) have allowed reliable recognition and definition of species-limits. This permitted the creation of an historical phylogenetic basis for each species. The availability of an historical phylogenetic backbone for species level diversity has provided a foundation to explore population structure relevant to: (1) understanding the drivers for contemporary patterns of geographic and host distribution; (2) faunal structure in space and time; and (3) the processes associated with maintenance and emergence of Trichinella infections in humans and food animals (Rosenthal et al., 2008; Hoberg and Brooks, 2008). Furthermore, a comparative framework now exists (Brooks and McLennan, 2002) against which continued exploration and discovery of previously unrecognized diversity can be assessed. These issues are addressed in the section to follow. 


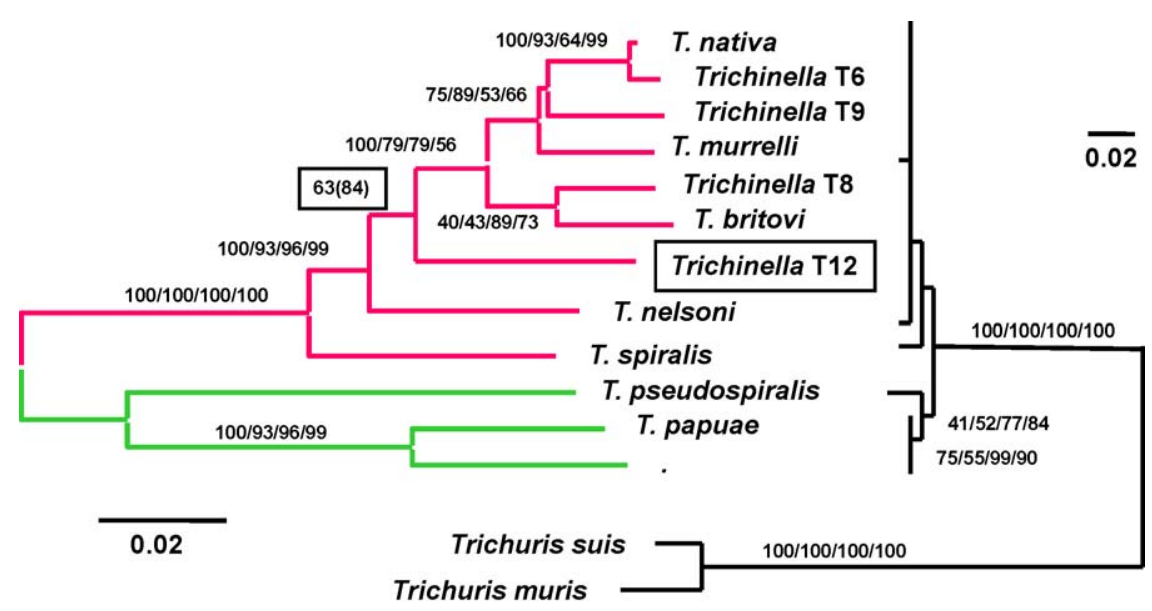

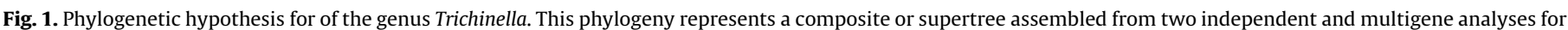

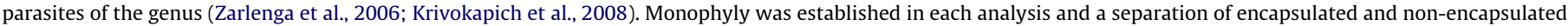

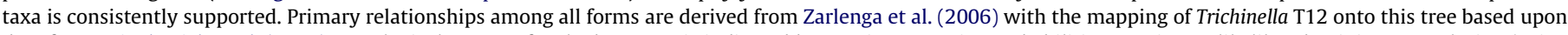

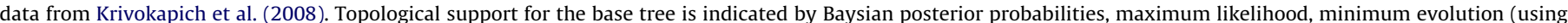

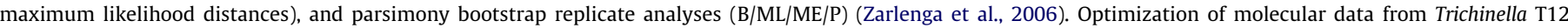

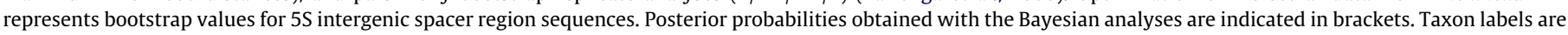
consistent with these analyses and with the text. Bars indicate base substitutions per site.

\section{Biogeography and host associations}

The lineage representing Trichinella is archaic and estimates for divergence from a common ancestor for Trichuridae and Trichinellidae, based on a molecular clock, extend to the late Paleozoic or early Mesozoic, 250-300 Ma (Zarlenga et al., 2006). The appearance of extant species and genotypes is linked to events in the late Tertiary and appears associated with Eutherian mammals (Zarlenga et al., 2006). An exploration of host and geographic associations relative to phylogenetic hypotheses (Fig. 2) reveals: (1) the separation between Trichinellidae and the putative sistergroup Trichuridae may coincide with initial diversification of terrestrial tetrapods (Zarlenga et al., 2006, 2009); (2) contemporary fauna initially diversified in Eurasia followed by relatively recent (20-30 Ma) basal divergence between the encapsulated and non-encapsulated clades; (3) each clade contains species that are geographically and ecologically restricted, and only two species have cosmopolitan distributions due to the spread by birds ( $T$. pseudospiralis) or by anthropogenic activity (T. spiralis) (La Rosa et al., 2003b; Rosenthal et al., 2008); (4) diversification is associated with episodes of biotic expansion at intercontinental scales in the context of dynamic trophic linkages within foraging guilds (Hoberg and Brooks, 2008); and (5) subsequent isolation with carnivoran hosts occurred within specific time frames in the Miocene, Pliocene and Quaternary.

Alternating episodes of geographic expansion and isolation for faunas on varying temporal and spatial scales, as well as ecological fitting (a determinant of host switching) are postulated in the historical biogeography and diversification of carnivorans and omnivorous mammalian hosts and their parasites (Halas et al., 2005; Folinsbee and Brooks, 2007; Agosta and Klemens, 2008; Hoberg and Brooks, 2008). Yet, there is minimal evidence for a history of cospeciation for Trichinella among eutherians. This is consistent with host colonization rather than coevolution as a major driver for diversification in lineages involving complex hostparasite associations.

\subsection{Trichinella species/genotypes and their associated hosts}

Diversification for Trichinella can be linked to radiation of an ancestral assemblage of omnivores, carnivores and scavengers that constitute the range of contemporary hosts (Murrell et al., 2000; Kapel, 2000). Patterns of persistence, host association and diversification differ considerably among the 2 clades of Trichinella. Non-encapsulated forms appear to be relicts of a basal diversification in the Oligocene to Miocene followed by independent and secondary colonization among Eutheria, Metatheria, Aves, Squamata and Crocodilia. These non-encapsulated genotypes also retained plesiomorphic attributes for broad infectivity of tetrapods (e.g., Pozio et al., 2004). Encapsulated forms, on the other hand, radiated through host-switching within guild assemblages among Mustelidae, Ursidae, Canidae, Felidae and Hyaenidae in specific regional/continental settings. This radiation coincided with faunal expansion and geographic isolation during climatological and ecological perturbations in the Miocene, late Pliocene and Pleistocene (Zarlenga et al., 2006; Hoberg and Brooks, 2008) (Fig. 2). Carnivorans including felids, hyaenids and viverrids (Feloidea), canids, ursids, mustelids (Arctoidea), and omnivores including Suidae radiated in Eurasia. These host groups have a history of differential arrival and temporal durations in Africa, the Nearctic and the Neotropics ranging from the lower Miocene to the Quaternary (e.g., Cooke and Wilkinson, 1978; Savage, 1978; Briggs, 1995; Johnson et al., 2006; Folinsbee and Brooks, 2007).

Encapsulated species of Trichinella principally represent a Eurasian/African group with secondary connections to the Holarctic and Neotropical faunas (Fig. 2). Ecological transitions from omnivory to facultative and obligate carnivory among mammalian hosts are recognized in the transmission dynamics of $T$. spiralis, $T$. nelsoni and the crown species of encapsulated Trichinella, respectively; the later is represented predominantly among arctoid carnivorans. Based on the distribution of genetic diversity, the origins for T. spiralis and the encapsulated clade are postulated in central Eurasia (Zarlenga et al., 2006). Global translocation of infected domesticated mammals, only recently perpetuated $T$. spiralis through a largely synanthropic cycle involving swine and possibly rats (Rosenthal et al., 2008).

Expansion of Trichinella from Eurasia to Africa is consistent with the history of carnivore and omnivore hosts (Cooke and Wilkinson, 1978; Savage, 1978; Folinsbee and Brooks, 2007). Three independent events are recognized (Fig. 2) and account for T. nelsoni, Trichinella T8, and the more contemporary distribution of $T$. britovi in north-western Africa (Pozio et al., 2005a; Pozio and Murrell, 2006). Trichinella nelsoni, which is confined to sub-Saharan Africa, 


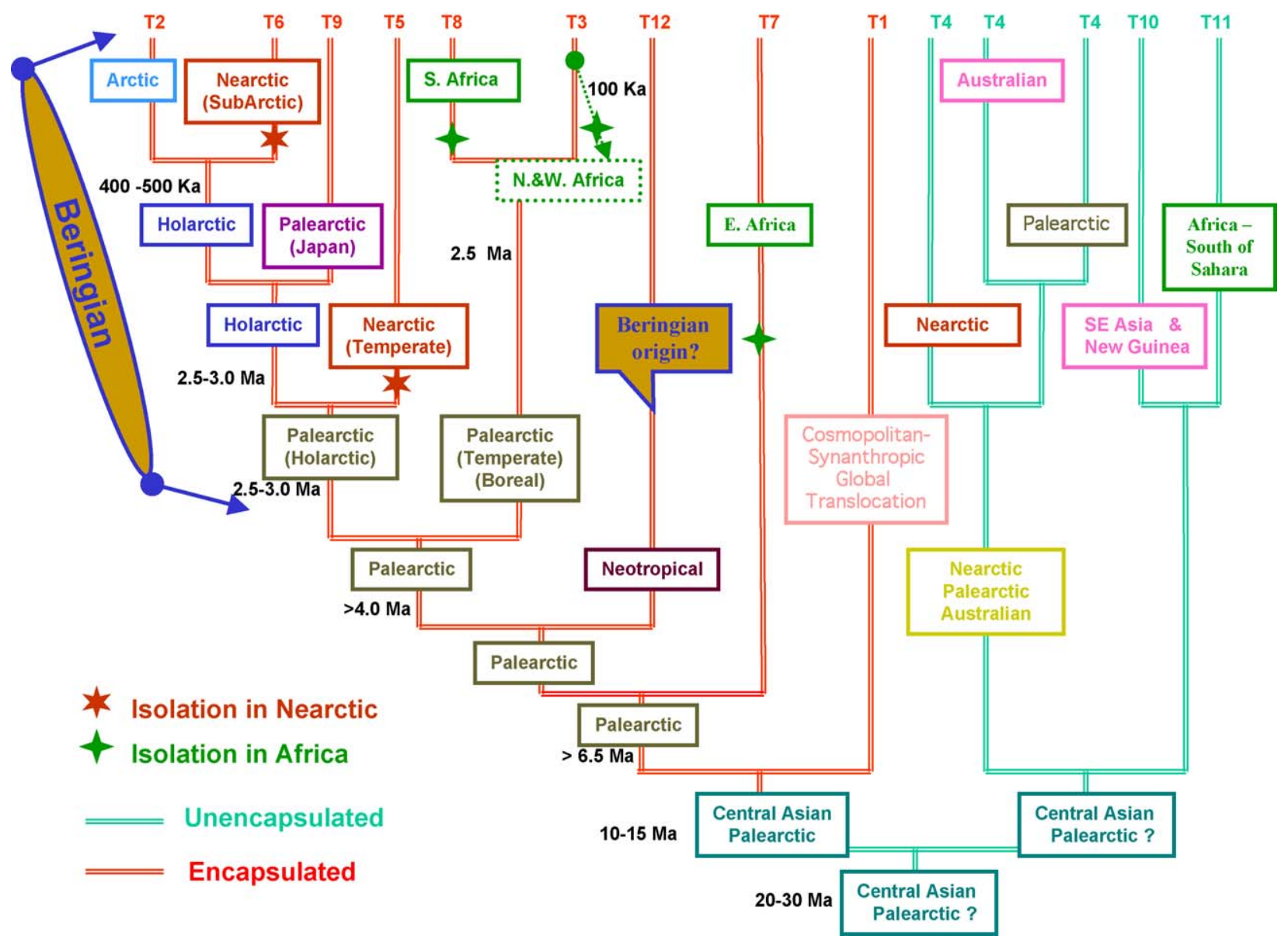

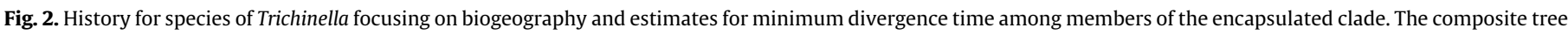

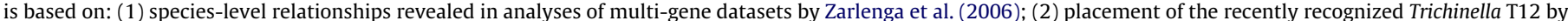

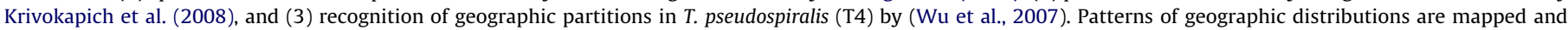

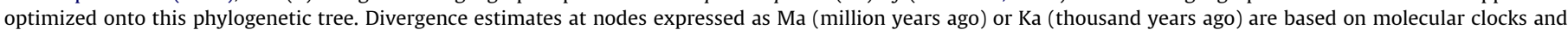

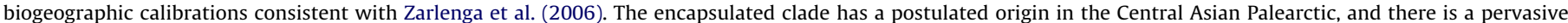

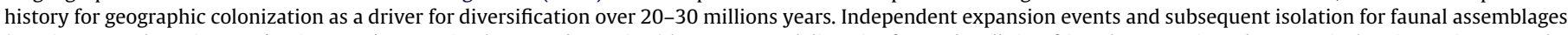

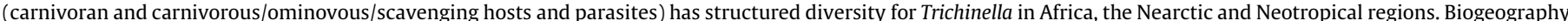

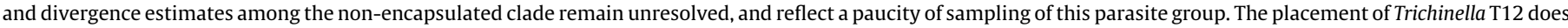

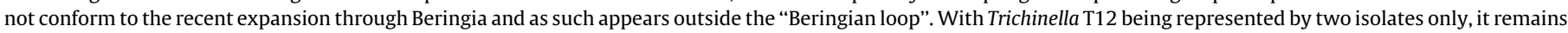

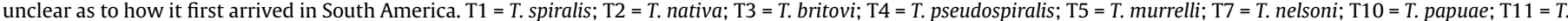
zimbabwensis; T6, T8, T9 and T12 represent unnamed Trichinella genotypes currently designated by numbers only.

mainly circulates among felids, and hyaenids (Pozio et al., 1997b; Marucci et al., 2009).

Area relationships indicate that biotic expansion with primary carnivore host groups occurred first across Eurasia into Western Europe (T. britovi) (>6.5 Ma), and then across Beringia into North America (<3.0 Ma) (Fig. 2). This is compatible with a shallow history for extant species of Trichinella in the Nearctic and across the Holarctic. Recent divergence among Nearctic species of Trichinella is consistent with the minimal genetic variation among T. murrelli (temperate Nearctic), Trichinella T9 (Japan), T. nativa (high latitude Holarctic) and Trichinella T6 (SubArctic Nearctic) (Zarlenga et al., 2006). Trichinella britovi has a continuous distribution across the Palearctic (Pozio and Murrell, 2006) and is represented by expansion into northern and western Africa in the late Pleistocene (Pozio et al., 2005a). Radiation among crown species was associated with independent events of expansion across Beringia during the Pleistocene. This radiation was temporally decoupled, and coincided with a narrowing of the host range to primarily arctoid carnivorans, and the development of a freeze-resistant phenotype in the crown species.

Separation of the South America from Africa began about 150 million years ago; however, the infiltration of the sea between the two continents was intermittent up until about 92 million years ago when the land masses finally separated. The recently discovered Trichinella T12 in Patagonia may represent the outcome of expansion of Eurasian felids through the Nearctic into the Neotropical region after $8 \mathrm{Ma}$ and suggests that this parasite circulates primarily in felids and canids (Johnson et al., 2006; Krivokapich et al., 2008). Although procyonids, canids, and mustelids underwent range expansion and extensive radiation following emergence of the Panamanian Isthmus and faunal interchange during the Pliocene/ Pleistocene 3.0 Ma (Marshall et al., 1982), to date, pre-existing associations with Trichinella have not yet been identified.

Recent expansion of extant genotypes through North America and into South America may have been followed by some level of extinction in the northern territories. Ecological conditions in South America were apparently not conducive to establishment and transmission of sylvatic Trichinella among northern eutherian carnivores and southern marsupials. Among sylvatic Trichinella with adaptations for survival in harsh, cold, and xeric environments, historical constraints and canalization with respect to life history may have constituted limitations on range expansion into the Neotropics where the Panamanian Isthmus represented a tropical filter bridge for the northern fauna in the late Tertiary. 
Thus, it is interesting that Trichinella T12 has affinities directly to Eurasia rather than to the Nearctic (Fig. 2), and suggests expansion across Beringia during times of relatively mild climate prior to the late Pliocene and Quaternary. Clearly there are biogeographical concepts which remain unresolved; however, an understanding of macroevolutionary processes for the diversification, ecological structure and biogeography of Trichinella provides the framework to explore microevolutionary hypotheses linking regional faunas and events in ecological time and at fine spatial scales (Hoberg and Brooks, 2008).

\section{The International Trichinella Reference Centre and species identification}

Comparative studies within Trichinella have only been possible through the development and maintenance of archival collections which are the foundations for studies in biodiversity (e.g., Hoberg, 2002). A major resource that has provided vital parasite material and information for these studies is the International Trichinella Reference Centre (ITRC; www.iss.it/site/Trichinella/index.asp). This centre was established in 1988 and has become the official reference laboratory of both the International Commission on Trichinellosis (since 1988; www.med.unipi.it/ict/welcome.htm) and the World Organization for Animal Health (since 1992; www.oie.int/eng/en_index.htm). The ITRC was created as a repository for Trichinella strains and as a source of materials and information for international research and diagnosis of Trichinella isolates (Pozio et al., 1989, 2001). Today, the ITRC contains data on more than 2300 isolates from around the world. In addition to molecular typing, information on each isolate includes their host species, geographical origin, and other epidemiological information. More than 80 isolates are continually maintained in vivo. The predominant modes of identification involve multiplex PCR (Zarlenga et al., 1999; Pozio and La Rosa, 2003) and when necessary, DNA sequencing. Multiplex PCR is based upon concurrent amplification of expansion segment $\mathrm{V}$ from the lsu rRNA gene for all Trichinella genotypes along with specific primers from the ITS1 and ITS2 that are diagnostic for individual taxon. Unique agarose gel banding profiles are generated from a mixture of 5 different primer pairs. That which follows is a compilation of multiplex PCR, biological and biochemical information available through the ITRC for each specie and genotype of Trichinella presented according to their classification within the encapsulated and non-encapsulated clades.

\subsection{The encapsulated clade}

Today, five species and four genotypes are recognized in this clade (Table 2).

\subsubsection{Trichinella spiralis}

Trichinella spiralis was the first discovered species and remains today the cause of most infections in domestic animals (pigs and horses) and humans. Worldwide, this species has been detected in 36 countries spanning all continents (Pozio, 2007b). Most Trichinella infections in humans are caused by this species which can also induce death (Dupouy-Camet et al., 2002). By multiplex PCR, parasites of this species display a single band of $173 \mathrm{bp}$ from the ESV (Zarlenga et al., 1999). Although this parasite can develop in many mammalian species belonging to different families, the main reservoir is represented by domestic and sylvatic swine within which the parasite can attain very high worm burdens (more than 3000 larvae/g) without any adverse physiological effects, suggesting a very good host-parasite relationship (Kapel and Gamble, 2000; Kapel, 2001). This species is the most important etiological agent of the domestic cycle and it occurs with high prevalence in areas with limited or no veterinary control at the slaughterhouses, and where free-ranging and backyard pigs are slaughtered in the absence of veterinary controls. In regions or countries where this parasite was at one time common within the domestic cycle (e.g., Germany, Poland, Spain), high prevalence rates can still be detected in wild boars (Pozio et al., 2009). In Europe, $T$. spiralis has been discovered in $82 \%, 62 \%, 82 \%$ and $11 \%$ of Trichinella-infected domestic pigs, wild boars, synanthropic brown rats and sylvatic carnivores, respectively (Pozio et al., 2009). In America, $T$. spiralis was identified as the etiologic agent in all but one of the 50 isolates originating from swine (domestic and sylvatic). In addition, T. spiralis has been found in 10 carnivores (i.e., bears, bobcat, coyote, feral cat, red fox and mountain lion) accounting for $19 \%$ of Trichinella-infected carnivores, and in 5 synanthropic animals (armadillos and brown rats) captured near $T$. spiralis-infected pig farms (www.iss.it/site/Trichinella/index.asp). The ability to perform PCR on single larvae (up to 1/10 of a larva; La Rosa G. unpublished information) has allowed the identification of mixed infections in animals from regions where $T$. spiralis lives in sympatry with T. nativa, T. britovi, T. murrelli or T. pseudospiralis (www.iss.it/site/Trichinella/index.asp). This has advanced our understanding of the potential for gene flow between sympatric species and genotypes (Pozio et al., 1995, 1997a; Oivanen et al., 2002; La Rosa et al., 2003a; Malakauskas et al., 2007).

\subsubsection{Trichinella nativa}

This species infects predominantly wild carnivore mammals of the families Canidae, Felidae, Mustelidae, Ursidae, Odobenidae, and very rarely Phocidae, living in arctic and subarctic areas of the Holarctic region. The southern distribution boundary has been tentatively identified between the isotherms -5 and $-4{ }^{\circ} \mathrm{C}$ in January (Pozio and Zarlenga, 2005). Infections in humans have been documented for the consumption of game meat (e.g., bears and walruses). Experimental infections have shown that few $T$. nativa larvae can develop to L1 in swine muscles and those that develop are rapidly (within 10 weeks p.i.) destroyed by a natural immune response (Kapel and Gamble, 2000; Kapel, 2001). Nonetheless, $T$. nativa has been identified in $3.5 \%$ of Trichinella isolates from wild boars from countries where it was circulating among wild carnivores (www.iss.it/site/Trichinella/index.asp). Mixed infections have been identified in regions where $T$. nativa lives in sympatry with $T$. spiralis, T. britovi and Trichinella T6. By multiplex PCR, parasites of this species display a band of $127 \mathrm{bp}$ from the ESV (Zarlenga et al., 1999) which is the same as Trichinella T12 (see below); however, the two taxa can be easily distinguished by sequencing the amplicon. Also, the $127 \mathrm{bp}$ fragment from ESV is common to most encapsulated sylvatic genotypes and differentiation by multiplex PCR for this group of worms is predicated upon multiple primer sets for each genotype. A secondary primer set has yet to be developed for Trichinella T12 to delineate it from T. nativa. One interesting biological peculiarity of this species is its high resistance to freezing in muscles of carnivores (up to 5 years) (Dick and Pozio, 2001). This biological character is lost, however, in frozen muscles of swine and rodents (Kapel, 2000; Malakauskas and Kapel, 2003), suggesting some level of host-parasite relationship with respect to $T$. nativa and obligate carnivores.

\subsubsection{Trichinella britovi}

This species is most often found in wild carnivore mammals of the families of Canidae, Felidae, Mustelidae, Ursidae, and Viverridae, living in temperate regions of Europe, Western Asia, and Northern and Western Africa (Pozio and Murrell, 2006). The northern distribution boundary has been tentatively defined as the isotherms -5 and $-6{ }^{\circ} \mathrm{C}$ in January (Pozio and Zarlenga, 2005). In Europe, $T$. britovi has been detected in $89 \%, 38 \%$ and $18 \%$ of Trichinella isolates from carnivores, wild boars and domestic pigs, respectively (Pozio 
et al., 2009). Even if T. britovi can infect domestic and sylvatic swine, survival of the larvae in striated muscles of these hosts rarely exceeds 6-9 months which may explain the apparent lower prevalence relative to $T$. spiralis. Similar to $T$. nativa, $T$. britovi can survive in frozen muscles of carnivores but for shorter periods of time (less than 1 year), and in frozen swine muscles only for few weeks (Dick and Pozio, 2001; Pozio et al., 2006). Human infections have resulted from the consumption of free-ranging and backyard pigs, horse meat, and game meat. By multiplex PCR, parasites of this species display a band at 127 bp derived from the ESV as well as a second band at $253 \mathrm{bp}$ from the ITS1 (Zarlenga et al., 1999). This profile is identical to the one generated by Trichinella genotypes T8 and T9; however, the three taxa can be distinguished by additional PCR analysis (see below) and by geographical origin, because they are allopatric. Enzymatic amplification of single larvae has revealed mixed infections in animals from regions where $T$. britovi lives in sympatry with $T$. spiralis and $T$. nativa.

\subsubsection{Trichinella murrelli}

This species is the vicariant species of $T$. britovi in North America since it circulates among carnivores in this temperate geographical region only (Pozio and La Rosa, 2000). The main hosts are wild carnivore mammals of the families of Canidae, Felidae, Procyonidae and Ursidae. There is a single report in 1985 of $T$. murrelli in horsemeat in France that was the source of a large human outbreak with two deaths (Ancelle et al., 1988); however, it was later determined that this was imported from Connecticut (USA). This species does not develop in domestic and wild swine (Kapel and Gamble, 2000; Kapel, 2001). By multiplex PCR, T. murrelli displays a band at $127 \mathrm{bp}$ from the ESV and a second band at $316 \mathrm{bp}$ from the ITS2 (Zarlenga et al., 1999). A mixed infection of T. murrelli and $T$. spiralis was detected in a black bear from California (www.iss.it/ site/Trichinella/index.asp).

\subsubsection{Trichinella nelsoni}

This species has been detected in Eastern Africa from Kenya to South Africa (Pozio et al., 1997b; Marucci et al., 2009). Trichinella nelsoni infects predominantly wild carnivore mammals belonging to the families Canidae, Felidae, Hyaenidae and Viverridae, but it has been also detected in warthogs (Pozio and Murrell, 2006). Human infections have been documented only rarely from the consumption of warthog or bush pig meat with some deaths (Pozio, 2007b). By multiplex PCR, parasites of this species display a band at 127 bp derived from the ESV and a second band at $404 \mathrm{bp}$ from the ITS2 (Zarlenga et al., 1999). Genetic variants have been detected among parasites originating from different geographical regions (La Rosa and Pozio, 2000). A mixed infection containing $T$. nelsoni and Trichinella T8 has been documented in a lion from the Kruger National Park of South Africa (Marucci et al., 2009).

\subsubsection{Trichinella $T 6$}

This freeze resistant genotype infects only wild carnivore mammals belonging to the families of Canidae, Felidae, Mustelidae and Ursidae, and circulates in USA and Canada quite frequently in sympatry with $T$. nativa. Inasmuch as hybrid larvae between Trichinella T6 and T. nativa have been detected in nature (La Rosa et al., 2003a), the taxonomic status of Trichinella T6 remains undefined. Human infections have been rarely documented for the consumption of carnivore meat (Pozio and Murrell, 2006). By multiplex PCR, parasites of this species display a band at $127 \mathrm{bp}$ from the ESV and a second band at $210 \mathrm{bp}$ from the ITS1 (Zarlenga et al., 1999).

\subsubsection{Trichinella $T 8$}

This genotype is phylogenetically related to $T$. britovi with which it interbreeds and produces fertile offspring. It has been discovered only in lions and spotted hyaenas from the Kruger National Park of South Africa and from the Etosha National Park in Namibia (Pozio et al., 1994; Marucci et al., 2009). No human infections have been documented. By multiplex PCR, parasites of this species display a band of 127 bp from the ESV and a band of 253 bp from the ITS1 (Zarlenga et al., 1999), i.e. the same pattern displayed by $T$. britovi; however, these two taxa can be differentiated by a PCR based on a 21 bp deletion in the ITS2 sequence of Trichinella T8 (Pozio et al., 2005a).

\subsubsection{Trichinella $T 9$}

This genotype is phylogenetically related to T. murrelli (Zarlenga et al., 2006) with which it interbreeds and produces fertile offspring (Pozio E., unpublished data). It has been found among wild carnivores belonging to the Canides and Ursidae of Japan only (Kanai et al., 2007). No human infections have been documented. By multiplex PCR, parasites of this species display a band of $127 \mathrm{bp}$ from the ESV and a second band of 253 bp derived from the ITS1 (Zarlenga et al., 1999), i.e. the same pattern displayed by T. britovi; however, these two taxa can be distinguished by PCR-RFLP based on the COI mitochondrial DNA (Nagano et al., 1999).

\subsubsection{Trichinella $T 12$}

This newly recognized genotype was identified in pumas (Puma concolor) from Patagonia, Argentina. By multiplex PCR, parasites of this taxon display a band of $127 \mathrm{bp}$ of the ESV as T. nativa for reasons described under T. nativa above; however, the two taxa can be easily distinguished by sequencing this amplicon (Krivokapich et al., 2008). Comparative analysis of DNA sequences from COI and 5S ISR differentiates Trichinella T12 from all the other recognized Trichinella species or genotypes so far identified (Krivokapich et al., 2008); however, no biological and epidemiological information is available. Bootstrap data were equivocal in the relative positioning of T. spiralis, T. nelsoni and Trichinella T12 from Patagonia (Fig. 1). Nonetheless, establishment of the most probable phylogenetic position of this genotype in the encapsulated clade can represent an important step to our knowledge on the expansion and biogeography of encapsulated species.

\subsection{The non-encapsulated clade}

Trichinella species belonging to this clade can be further subdivided into two groups; those that circulate among mammals and birds, and those that infect mammals and reptiles (Table 2).

\subsubsection{Trichinella pseudospiralis}

Trichinella pseudospiralis was first discovered in 1972 . This nonencapsulated species was considered an enigma for a decade since only one isolate had been detected. Larvae are able to infect both mammals and birds but do not induce a thick collagen capsule around the nurse cell complex (Dick, 1983). Worldwide isolation of these parasites from mammals and birds has permitted studies on the global distribution of this specie and its host preference (Pozio and Murrell, 2006). By multiplex PCR, T. pseudospiralis from Eurasia, North America and Tasmania, display bands at 310,340, or 360 bp from the ESV, respectively (Zarlenga et al., 1996, 1999; La Rosa et al., 2001). Of 33 isolates identified so far at the ITRC, 14 originated from domestic and sylvatic swine, ten from carnivore mammals, four from carnivore birds, three from synanthropic rodents near farms harbouring $T$. pseudospiralis-infected pigs, one from a carnivore marsupial from Tasmania, and one from a man who acquired the infection from wild pig meat in Thailand (www.iss.it/site/Trichinella/index.asp; Jongwutiwes et al., 1998). Inasmuch as the numbers of different animals and birds examined for Trichinella varies greatly, the natural cycle of this parasite and any host preferences remain enigmas. 


\subsubsection{Trichinella papuae}

The circulation of Trichinella parasites (initially thought to be $T$. spiralis) in New Guinea was first reported by Madsen in 1964 (Anonymous, 1964). This information became buried in the literature until 1988, when non-encapsulated larvae of Trichinella were discovered in "backyard pigs" from a remote region of Papua New Guinea (PNG) (Owen et al., 2000). The combination of molecular and biological data permitted classifying these parasites as a new species (Pozio et al., 1999a). By multiplex PCR, parasites of this species display a unique band of 240 bp derived from the ESV. As with T. pseudospiralis, this amplified product shows sequence heterogeneity among isolates originating from different regions of PNG (Pozio et al., 2005b). So far, this species has been detected in backyard pigs, wild pigs and farmed saltwater crocodiles in PNG. In addition, T. papuae was identified in two wild pigs from Thailand which were the sources of two human outbreaks (Khumjui et al., 2008; www.iss.it/site/Trichinella/index.asp). A high level of infection has been documented in humans living in remote regions of PNG (Owen et al., 2005). Muscle larvae from naturally-infected wild pigs retained their infectivity up to nine days after being slaughtered and left in a tropical environment $\left(35^{\circ} \mathrm{C}, 79.0 \%\right.$ of relative humidity). This is consistent with the adaptability of this parasite to extreme environmental conditions which in turn favours its transmission to new hosts (Owen and Reid, 2007).

\subsubsection{Trichinella zimbabwensis}

In 1995, Trichinella larvae were detected in the muscles of farmed crocodiles (Crocodylus niloticus) in Zimbabwe (Pozio et al., 2002). This represented the first observation of a reptile species naturally-infected with Trichinella and in poikilothermic animals. Molecular, biochemical and biological studies demonstrated that these parasites constituted a new species able to infect both reptiles and mammals (Pozio et al., 2002, 2004, 2007c). In addition, host-tissue morphology also showed that indeed, this species belonged in the non-encapsulated clade. By multiplex PCR, parasites of this species display a unique band of $264 \mathrm{bp}$ from the ESV. Sequence heterogeneity has been observed among isolates originating from different regions of Zimbabwe and South Africa (Pozio et al., 2007c; La Grange et al., 2009). As the number of identified isolates has increased, our knowledge of the geographical range of $T$. zimbabwensis has been expanded to Ethiopia, Mozambique, and to South Africa where it was detected also in a lion (www.iss.it/site/Trichinella/index.asp). No human infections have been reported to date.

\section{Open issues}

\subsection{T. spiralis and T. britovi in carnivores}

According to studies involving experimental infections (Kapel, 2000), the red fox is an excellent host for T. spiralis; however, epidemiological data from Europe (Pozio et al., 2009), indicate that the percentage of foxes infected with T. spiralis (10\%) is much lower than the percentage infected with $T$. britovi (90\%). It is not yet known if this discrepancy is related to the entozoic habitat of the fox or its behaviour. If associated with the entozoic habitat, the difference between experimental and natural infections could be related to variations in survival times between the two Trichinella species in fox muscle tissue. This issue was not addressed in the studies conducted by Kapel (2000) because the experimental infections were carried out over short duration times only. Likewise, if the discrepancy is related to feeding behaviour, experimental infections would not account for the natural acquisition of $T$. spiralis. Inasmuch as the prevalence of $T$. spiralis is very low (Rafter et al., 2005; Pozio, 2007b) or non-existent (e.g. Great Britain, Sicily) (Pozio and La Rosa, 1998; Zimmer et al., 2008) in fox populations where wild boar do not exist (e.g., Ireland, Ulster), the fox may not be a good reservoir for T. spiralis in nature even though it is an excellent experimental host. The data further suggest that the natural reservoir of this parasite species, i.e. the wild boar, may be required to propagate $T$. spiralis infections among local populations of foxes.

\subsection{Relationship between T. nativa and Trichinella T6}

As reported above, T. nativa and Trichinella T6 have been found in sympatry, i.e. in the same host above the January $-4{ }^{\circ} \mathrm{C}$ isotherm in North America. Natural hybrids have been identified also (La Rosa et al., 2003a; Reichard et al., 2008). Breeding experiments between T. nativa and Trichinella $\mathrm{T} 6$ produced $\mathrm{F} 1$ viable offspring in both senses (male T. nativa $\mathrm{x}$ female $\mathrm{T}$, and female T. nativa $\mathrm{x}$ male $\mathrm{T} 6$ ); however, only $\mathrm{F} 1$ larvae originating from male $T$. nativa $\mathrm{x}$ female T6 were able to produce viable F2 offspring (La Rosa et al., 2003a). As such, the evolution of these two taxa is perplexing given they share the same hosts, T. nativa spans the Holarctic, and to date Trichinella T6 has not been found in the Palearctic. Numerous hypotheses have been advanced based upon constraints imposed by the tree topology (Fig. 1). One advocates Trichinella T9 as a peripheral isolate on the islands of Japan. If so, the divergence of $T$. nativa and Trichinella T6 may have occurred during episodes of allopatry in Beringia and in periglacial habitats south of the Cordilleran and Laurentide glaciers resulting in a bifurcation of the freeze-resistant genotype possibly as far west as the Rocky Mountains (La Rosa et al., 2003a; Zarlenga et al., 2006). A second hypothesis assumes that peripheral isolation played a role in diversifying these two crown species where T. nativa may represent an ancestral and persistent high-latitude population in the Holarctic (Zarlenga et al., 2006). Although not constrained by the current tree topology, a third hypothesis suggests that T. nativa first evolved in the more frigid zones of the Palearctic and Trichinella T6 appeared in the Nearctic only recently after biotic expansion of T. nativa through Beringia. However, new freezeresistant, geographical isolates representing these genotypes will be required to shed light on this issue.

\subsection{What is the natural cycle for T. pseudospiralis?}

Trichinella pseudospiralis infects both mammals and birds, and has been detected inconsistently in less than 20 countries worldwide (Pozio, 2007b). Its prevalence in examined animals is always very low when compared to other Trichinella species circulating in the same regions (www.iss.it/site/Trichinella/index.asp). To date, collected data do not allow assignment of a natural host or host group for this parasite. This is due in part to a bias in the types and numbers of animals tested for Trichinella. Among the thousands of animals examined each year for Trichinella, the number of birds as well as the number of rodents and insectivores is less than a few hundred. Inadvertently, this may be generating the very low number of findings in birds. However, as the number of omnivorous birds such as seagulls, crows and rocks increases in many parts of the world, the opportunities to monitor for T. pseudospiralis infections should increase as well. The continued use of molecular techniques will allow more thorough investigations of the role of different animal species in the natural cycle of this parasite.

\subsection{Intraspecific population variation}

Based upon microsatellite data from ESV of the lsu rRNA gene, Zarlenga et al. (1996) were first to propose that the nonencapsulated species $T$. pseudospiralis might best be envisioned as a group of independently evolving genotypes. They found both population differences as well as multiple alleles in the lsu rRNA 
gene. This was corroborated by La Rosa et al. (2001) and most recently by Wu et al. (2007) who used ten isolates and nine different genes to conclude that T. pseudospiralis from Australia, the Nearctic and the Palearctic were indeed distinct. This laid the ground work for more extensive studies of DNA microsatellites and how they could assist in understanding Trichinella evolution. Since those initial studies, intraspecific genetic variation has been observed in the other non-encapsulated species as well (Pozio et al., 2005b; Pozio et al., 2007c); however, this variation was not relegated to the non-encapsulated clade. Genetic variation was observed in geographical isolates of T. nelsoni as early as 2000 (La Rosa and Pozio, 2000) and by single sequence conformational polymorphism in 2004 (Gasser et al., 2004). Most recently, using microsatellite markers, Rosenthal et al. (2008) found that variation exists within virtually all species and genotypes examined. A study of nine microsatellite loci and sequencing one-fifth of the mitochondrial genome of $T$. spiralis from America, Asia, Europe and North Africa showed that parasites from this species are remarkably uniform worldwide except for $T$. spiralis in Asia, where swine were first domesticated and genetic variability in $T$. spiralis is greater than that found in the West (Rosenthal et al., 2008). These results support the hypothesis that European lineages of $T$. spiralis originated several thousands of years ago, approximating the time when pigs were first domesticated. These population studies also corroborated the hypothesis that extant encapsulated Trichinella likely had origins in Asia and that European travellers or those travelling through Western Europe inadvertently introduced $T$. spiralis to the Americas via infected pigs and/or rats (Rosenthal et al., 2008).

\section{Conclusions}

In recent years a well corroborated hypothesis for relationships among the 12 recognized genotypes and species of Trichinella has been generated. This hypothesis supports the taxonomic scheme that has evolved over the past 25-35 years predicated on numerous biological and biochemical characters that have been amassed by the ITRC. This working tree now provides a foundation to explore the fine scale history of parasite populations using a deeper historical background. Clearly, as new isolates are identified, they should help expand and clarify our understanding of the diversity and evolutionary forces which been active in recent evolutionary time.

\section{References}

Agosta, S.J., Klemens, J.A., 2008. Ecological fitting by phenotypically flexible genotypes: implications for species associations, community assembly and evolution. Ecol. Lett. 11, 1123-1134.

Ancelle, T., Dupouy-Camet, J., Bougnoux, M.E., Fourestie, V., Petit, H., Mougeot, G., Nozais, J.P., Lapierre, J., 1988. Two outbreaks of trichinosis caused by horsemeat in France in 1985. Am. J. Epidemiol. 127, 1302-1311.

Anonymous, 1964. Summary of the discussion. In: Corradetti, A., Ed., Proceedings of the 1st International Congress of Parasitology, Rome, September 21-26. Tamburini Editore, Milan, p. 697.

Appleyard, G.D., Zarlenga, D., Pozio, E., Gajadhar, A.A., 1999. Differentiation of Trichinella genotypes by polymerase chain reaction using sequence-specific primers. J. Parasitol. 85, 556-559.

Bandi, C., La Rosa, G., Comincini, S., Damiani, G., Pozio, E., 1993. Random amplified polymorphic DNA technique for the identification of Trichinella species. Parasitology 107, 419-424.

Bandi, C., La Rosa, G., Bardin, M.G., Damiani, G., Comincini, S., Tasciotti, L., Pozio, E. 1995. Random amplified polymorphic DNA fingerprints of the eight taxa of Trichinella and their comparison with allozyme analysis. Parasitology 110, 401407.

Blaxter, M.L., De Ley, P., Garey, J.R., Liu, L.X., Scheldeman, P., Vierstraete, A., Vanfleteren, J.R., Mackey, L.Y., Dorris, M., Frisse, L.M., Vida, J.T., Thomas, W.K., 1998. A molecular evolutionary framework for the phylum Nematoda. Nature 392, 71-75.

Briggs, J.C., 1995. Global biogeography. Elsevier, Amsterdam.

Britov, V.A., Boev, S.N., 1972. Taxonomic rank of various strains of Trichinella and their circulation in nature. Vestnik. Akademii. Nauk. KSSR 28, 27-32.
Brooks, D.R., McLennan, D.A., 2002. The Nature of Diversity: An Evolutionary Voyage of Discovery. University of Chicago Press, Chicago, USA.

Chambers, A.E., Almond, N.M., Knight, M., Simpson, A.J., Parkhouse, R.M., 1986. Repetitive DNA as a tool for the identification and comparison of nematode variants: application to Trichinella isolates. Mol. Biochem. Parasitol. 21, 113120.

Cooke, H.B.S., Wilkinson, A.F., 1978. Suidae and Tayassuidae. In: Maglio, V.J., Cooke, H.B.S. (Eds.), Evolution of African Mammals. Harvard University Press, Cambridge, pp. 435-482.

Dame, J.B., Murrell, K.D., Worley, D.E., Schad, G.A., 1987. Trichinella spiralis: genetic evidence for synanthropic subspecies in sylvatic hosts. Exp. Parasitol. 64, 195203.

De Ley, P., Blaxter, M.L., 2002. Systematic position and phylogeny. In: Lee, D.L. (Ed.), The Biology of Nematodes. Taylor \& Francis, London, pp. 1-30.

Dick, T.A., 1983. Species, and infraspecific variation. In: Campbell, W.C. (Ed.), Trichinella and Trichinosis. Plenum Press, New York and London, pp. 31-73.

Dick, T.A., Pozio, E., 2001. Trichinella spp. and trichinellosis. In: Samuel, W.M., Pybus, M.J., Kocan, A.A. (Eds.), Parasitic Diseases of Wild Mammals. 2nd ed. Iowa State University Press, Ames, pp. 380-396.

Dick, T.A., Lu, M.C., deVos, T., Ma, K., 1992. The use of the polymerase chain reaction to identify porcine isolates of Trichinella. J. Parasitol. 78, 145-148.

Dupouy-Camet, J., Kociecka, W., Bruschi, F., Bolas-Fernandez, F., Pozio, E., 2002 Opinion on the diagnosis and treatment of human trichinellosis. Expert Opin. Pharmacother. 3, 1117-1130.

Flockhart, H.A., Harrison, S.E., Dobinson, A.R., James, E.R., 1982. Enzyme polymorphism in Trichinella. Trans. R. Soc. Trop. Med. Hyg. 76, 541-545.

Folinsbee, K.E., Brooks, D.R., 2007. Miocene hominoid biogeography: pulses of dispersal and differentiation. J. Biogeogr. 34, 383-397.

Fukumoto, S., Takechi, M., Kamo, H., Yamaguchi, T., 1987. Comparative studies on soluble protein profiles and isozyme patterns of seven Trichinella isolates. Parasitol. Res. 73, 352-357.

Fukumoto, S., Nagai, D., Yazaki, S., Kamo, H., Yamaguchi, T., 1988. The molecular phylogenetic tree of the genus Trichinella constructed from isozyme patterns. Parasitol. Res. 74, 574-580.

Garkavi, B.L., 1972. Species of Trichinella isolated from wild animals. Veterinariya 10, $90-91$.

Gasser, R.B., Zhu, X.Q., Monti, J.R., Dou, L., Cai, X., Pozio, E., 1998. PCR-SSCP of rDNA for the identification of Trichinella isolates from mainland China. Mol. Cel. Probes 12, 27-34.

Gasser, R.B., Hu, M., Abs, EL-Osta, Zarlenga, D.S., Pozio, E., 2004. Non-isotopic singlestrand conformation polymorphism analysis of sequence variability in ribosomal DNA expansion segments within the genus Trichinella (Nematoda: Adenophorea). Electrophoresis 25, 3357-3364.

Halas, D., Zamparo, D., Brooks, D.R., 2005. A historical biogeographical protocol for studying diversification by taxon pulses. J. Biogeogr. 32, 249-260.

Hoberg, E.P., 2002. Foundations for an integrative parasitology: collections, archives and biodiversity informatics. Comp. Parasitol. 69, 124-131.

Hoberg, E.P., Brooks, D.R., 2008. A macroevolutionary mosaic: episodic host-switching, geographical colonization and diversification in complex host-parasite systems. J. Biogeogr. 35, 1533-1550.

Holterman, M., van der Wurff, A., van den Elsen, S., van Megen, H., Bongers, T. Holovachov, O., Bakker, J., Helder, J., 2006. Phylum-wide analysis of SSU rDNA reveals deep phylogenetic relationships among nematodes and accelerated evolution toward crown clades. Mol. Biol. Evol. 23, 1792-1800.

Johnson, W.E., Eizirik, E., Pecon-Slattery, J., Murphy, W.J., Antunes, A., Teeling, E., O'Brien, S.J., 2006. The late Miocene radiation of modern Felidae: a genetic assessment. Science 311, 73-77.

Jongwutiwes, S., Chantachum, N., Kraivichian, P., Siriyasatien, P., Putaporntip, C., Tamburrini, A., La Rosa, G., Sreesunpasirikul, C., Yingyourd, P., Pozio, E., 1998 First outbreak of human trichinellosis caused by Trichinella pseudospiralis. Clin. Infect. Dis. 26, 111-115.

Kanai, Y., Inoue, T., Mano, T., Nonaka, N., Katakura, K., Oku, Y., 2007. Epizootiological survey of Trichinella spp. infection in carnivores, rodents and insectivores in Hokkaido, Japan. Jpn. J. Vet. Res. 54, 175-182.

Kapel, C.M., 2000. Host diversity and biological characteristics of the Trichinella genotypes and their effect on transmission. Vet. Parasitol. 93, 263-278.

Kapel, C.M., 2001. Sylvatic and domestic Trichinella spp. in wild boars; infectivity, muscle larvae distribution, and antibody response. J. Parasitol. 87, 309-314.

Kapel, C.M., Gamble, H.R., 2000. Infectivity, persistence, and antibody response to domestic and sylvatic Trichinella spp. in experimentally infected pigs. Int. J. Parasitol. 30, 215-221.

Khumjui, C., Choomkasien, P., Dekumyoy, P., Kusolsuk, T., Kongkaew, W., Chalamaat, M., Jones, J.L., 2008. Outbreak of trichinellosis caused by Trichinella papuae, Thailand, 2006. Emerg. Infect. Dis. 14, 1913-1915.

Krivokapich, S.J., Prous, C.L., Gatti, G.M., Confalonieri, V., Molina, V., Matarasso, H. Guarnera, E., 2008. Molecular evidence for a novel encapsulated genotype of Trichinella from Patagonia, Argentina. Vet. Parasitol. 156, 234-240.

La Grange, L.J., Marucci, G., Pozio, E., 2009. Trichinella zimbabwensis in wild Nile crocodiles (Crocodylus niloticus) of South Africa. Vet. Parasitol. 161, 88-91.

La Rosa, G., Pozio, E., 2000. Molecular investigation of African isolates of Trichinella reveals genetic polymorphism in Trichinella nelsoni. Int. J. Parasitol. 30, 663667.

La Rosa, G., Pozio, E., Rossi, P., Murrell, K.D., 1992. Allozyme analysis of Trichinella isolates from various host species and geographical regions. J. Parasitol. 78 641-646. 
La Rosa, G., Marucci, G., Zarlenga, D.S., Pozio, E., 2001. Trichinella pseudospiralis populations of the Palearctic region and their relationship with populations of the Nearctic and Australian regions. Int. J. Parasitol. 31, 297-305.

La Rosa, G., Marucci, G., Zarlenga, D.S., Casulli, A., Zarnke, R.L., Pozio, E., 2003a. Molecular identification of natural hybrids between Trichinella nativa and Trichinella T6 provides evidence of gene flow and ongoing genetic divergence. Int. J. Parasitol. 33, 209-216

La Rosa, G., Marucci, G., Pozio, E., 2003b. Biochemical analysis of encapsulated and non-encapsulated species of Trichinella (Nematoda, Trichinellidae) from coldand warm-blooded animals reveals a high genetic divergence in the genus. Parasitol. Res. 91, 462-466.

Lavrov, D.V., Brown, W.M., 2001. Trichinella spiralis mtDNA: a nematode mitochondrial genome that encodes a putative ATP8 and normally structured tRNAS and has a gene arrangement relatable to those of coelomate metazoans. Genetics 157, 621-637.

Lichtenfels, J.R., Murrell, K.D., Pilitt, P.A., 1983. Comparison of three subspecies of Trichinella spiralis by scanning electron microscopy. J. Parasitol. 69, 1131-1140.

Maggenti, A.R., 1983. Nematode higher classification as influenced by species and family concepts. In: Stone, A.R., Platt, H.M., Khalil, L.F. (Eds.), Concepts in Nematode Systematics. Academic Press, London, pp. 25-40.

Malakauskas, A., Kapel, C.M., 2003. Tolerance to low temperatures of domestic and sylvatic Trichinella spp. in rat muscle tissue. J. Parasitol. 89, 744-748.

Malakauskas, A., Paulauskas, V., Järvis, T., Keidans, P., Eddi, C., Kapel, C.M., 2007. Molecular epidemiology of Trichinella spp. in three Baltic countries: Lithuania, Latvia, and Estonia. Parasitol. Res. 100, 687-693.

Marshall, L.G., Webb, S.D., Sepkoski, J.J., Raup, D.M., 1982. Mammalian evolution and the great American interchange. Science 215, 1351-1357.

Marucci, G., La Grange, L.J., La Rosa, G., Pozio, E., 2009. Trichinella nelsoni and Trichinella T8 mixed infection in a lion (Panthera leo) of the Kruger National Park (South Africa). Vet. Parasitol. 159, 225-228.

Meldal, B.H., Debenham, N.J., De Ley, P., De Ley, I.T., Vanfleteren, J.R., Vierstraete A.R., Bert, W., Borgonie, G., Moens, T., Tyler, P.A., Austen, M.C., Blaxter, M.L. Rogers, A.D., Lambshead, P.J., 2007. An improved molecular phylogeny of the Nematoda with special emphasis on marine taxa. Mol. Phylogenet. Evol. 42 622-636.

Mitreva, M., Jasmer, D.P., 2006. Biology and genome of Trichinella spiralis. In: The $C$ elegans Research Community, Eds., WormBook, pp. 1-21. doi/10.1895/wormbook.1.7.1, www.wormbook.org.

Mitreva, M., Jasmer, D.P., 2008. Advances in the sequencing of the genome of the adenophorean nematode Trichinella spiralis. Parasitology 135, 869-880.

Mitreva, M., Jasmer, D.P., Appleton, J., Martin, J., Dante, M., Wylie, T., Clifton, S.W., Waterston, R.H., McCarter, J.P., 2004. Gene discovery in the adenophorean nematode Trichinella spiralis: an analysis of transcription from three life cycle stages. Mol. Biochem. Parasitol. 137, 277-291.

Mitreva, M., Appleton, J., McCarter, J.P., Jasmer, D.P., 2005. Expressed sequence tags from life cycle stages of Trichinella spiralis: application to biology and parasite control. Vet. Parasitol. 132, 13-17.

Murrell, K.D., Stringfellow, F., Dame, J.B., Leiby, D.A., Duffy, C., Schad, G.A., 1987. Trichinella spiralis in an agricultural ecosystem. II. Evidence for natural transmission of Trichinella spiralis from domestic swine to wildlife. J. Parasitol. 73, 103-109.

Murrell, K.D., Lichtenfels, R.J., Zarlenga, D.S., Pozio, E., 2000. The systematics of the genus Trichinella with a key to species. Vet. Parasitol. 93, 293-307.

Mydynski, L.J., Dick, T.A., 1985. The use of enzyme polymorphisms to identify genetic differences in the genus Trichinella. J. Parasitol. 71, 671-677.

Nagano, I., Wu, Z., Matsuo, A., Pozio, E., Takahashi, Y., 1999. Identification of Trichinella genotypes by polymerase chain reaction-restriction fragment length polymorphism of mitochondrial cytochrome c oxidase subunit I gene. Int. J. Parasitol. 29, 1113-1120.

Nelson, G.S., 1970. Trichinosis in Africa. In: Gould, S.E. (Ed.), Trichinosis in Man and Animals. Charles C. Thomas Publisher, Springfield, IL, pp. 473-492.

Oivanen, L., Kapel, C.M.O., Pozio, E., La Rosa, G., Mikkonen, T., Sukura, A., 2002. Associations between Trichinella species and host species in Finland. J. Parasitol. $88,84-88$

Owen, R., 1835. Description of a microscopic entozoon infesting the muscles of the human body. Trans. Zool. Soc. London 1, 315-324.

Owen, I.L., Reid, S.A., 2007. Survival of Trichinella papuae muscle larvae in a pig carcass maintained under simulated natural conditions in Papua New Guinea. J. Helminthol. 81, 429-432.

Owen, I.L., Sims, L.D., Wigglesworth, M.C., Puana, I., 2000. Trichinellosis in Papua New Guinea. Aust. Vet. J. 78, 698-701.

Owen, I.L., Gomez Morales, M.A., Pezzotti, P., Pozio, E., 2005. Trichinella infection in a hunting population of Papua New Guinea suggests an ancient relationship between Trichinella and human beings. Trans. R. Soc. Trop. Med. Hyg. 99, 618 624.

Parkinson, J., Mitreva, M., Whitton, C., Thomson, M., Daub, J., Martin, J., Schmid, R., Hall, N., Barrell, B., Waterston, R.H., McCarter, J.P., Blaxter, M.L., 2004. A transcriptomic analysis of the phylum Nematoda. Nat. Genet. 36, 1259-1267.

Pozio, E., 1987. Isoenzymatic typing of 23 Trichinella isolates. Trop. Med. Parasitol $38,111-116$

Pozio, E., 2005. The broad spectrum of Trichinella hosts: from cold- to warm-blooded animals. Vet. Parasitol. 132, 3-11.

Pozio, E., 2007a. Taxonomy, biology and epidemiology of Trichinella parasites. In: Dupouy-Camet, J., Murrell, K.D. (Eds.), FAO/WHO/OIE Guidelines for the Surveillance, Management, Prevention and Control of Trichinellosis. World Organisation for Animal Health Press, Paris, pp. 1-35.
Pozio, E., 2007b. World distribution of Trichinella spp. infections in animals and humans. Vet. Parasitol. 149, 3-21.

Pozio, E., La Rosa, G., 1998. Short report: identification of the likely etiologic agent of human trichinellosis in Sicily (Italy) between 1933 and 1946. Am. J. Trop. Med. Hyg. 59, 906-907.

Pozio, E., La Rosa, G., 2000. Trichinella murrelli n. sp: etiological agent of sylvatic trichinellosis in temperate areas of North America. J. Parasitol. 86, 134-139.

Pozio, E., La Rosa, G., 2003. PCR-derived methods for the identification of Trichinella parasites from animal and human samples. Methods Mol. Biol. 216, 299-309.

Pozio, E., Murrell, K.D., 2006. Systematics and epidemiology of Trichinella. Adv. Parasitol. 63, 367-439.

Pozio, E., Zarlenga, D.S., 2005. Recent advances on the taxonomy, systematics and epidemiology of Trichinella. Int. J. Parasitol. 35, 1191-1204.

Pozio, E., La Rosa, G., Rossi, P., 1989. Trichinella Reference Centre. Parasitol. Today 5, 169-170.

Pozio, E., La Rosa, G., Murrell, K.D., Lichtenfels, J.R., 1992. Taxonomic revision of the genus Trichinella. J. Parasitol. 78, 654-659.

Pozio, E., Verster, A., Braack, L., De Meneghi, D., La Rosa, G., 1994. Trichinellosis south of the Sahara. In: Campbell, C.W., Pozio, E., Bruschi, F. (Eds.), Trichinellosis. ISS Press, Rome, Italy, pp. 527-532.

Pozio, E., Bandi, C., La Rosa, G., Järvis, T., Miller, I., Kapel, C.M., 1995. Concurrent Infection with sibling Trichinella species in a natural host. Int. J. Parasitol. 25, 1247-1250.

Pozio, E., Serrano, F.J., La Rosa, G., Reina, D., Perez-Martin, E., Navarrete, I., 1997a. Evidence of potential gene flow in Trichinella spiralis and in Trichinella britovi in Nature. J. Parasitol. 83, 163-166.

Pozio, E., De Meneghi, D., Roelke-Parker, M.E., La Rosa, G., 1997b. Trichinella nelsoni in carnivores from the Serengeti ecosystem, Tanzania. J. Parasitol. 83, 11951198.

Pozio, E., Owen, I.L., La Rosa, G., Sacchi, L., Rossi, P., Corona, S., 1999a. Trichinella papuae n. sp. (Nematoda), a new non-encapsulated species from domestic and sylvatic swine of Papua New Guinea. Int. J. Parasitol. 29, 1825-1839.

Pozio, E., Kapel, C.M., Gamble, H.R., 1999b. Specificity and sensitivity of random amplified polymorphic DNA analysis for the identification of single larvae of Trichinella after experimental infection of pigs. Parasitol. Res. 85, 504506.

Pozio, E., La Rosa, G., D’Ancona, F., Amati, M., Mancini Barbieri, F., De Giacomo, M., 2001. Twelve years of activity of the International Trichinella Reference Centre. Parasite 8, S44-S46.

Pozio, E., Foggin, C.M., Marucci, G., La Rosa, G., Sacchi, L., Corona, S., Rossi, P., Mukaratirwa, S., 2002. Trichinella zimbabwensis n.sp. (Nematoda), a new nonencapsulated species from crocodiles (Crocodylus niloticus) in Zimbabwe also infecting mammals. Int. J. Parasitol. 32, 1787-1799.

Pozio, E., Marucci, G., Casulli, A., Sacchi, L., Mukaratirwa, S., Foggin, C.M., La Rosa, G., 2004. Trichinella papuae and Trichinella zimbabwensis induce infection in experimentally infected varans, caimans, pythons and turtles. Parasitology 128, 333342.

Pozio, E., Pagani, P., Marucci, G., Zarlenga, D.S., Hoberg, E.P., De Meneghi, D., La Rosa, G., Rossi, L., 2005a. Trichinella britovi etiological agent of sylvatic trichinellosis in the Republic of Guinea (West Africa) and a re-evaluation of geographical distribution for encapsulated species in Africa. Int. J. Parasitol. 35, 955-960.

Pozio, E., Owen, I.L., Marucci, G., La Rosa, G., 2005b. Inappropriate feeding practice favors the transmission of Trichinella papuae from wild pigs to saltwater crocodiles in Papua New Guinea. Vet. Parasitol. 127, 245-251.

Pozio, E., Kapel, C.M., Gajadhar, A.A., Boireau, P., Dupouy-Camet, J., Gamble, H.R., 2006. Trichinella in pork: current knowledge on the suitability of freezing as a public health measure. Euro Surveill. 11 E061116.1.

Pozio, E., Foggin, C.M., Gelanew, T., Marucci, G., Hailu, A., Rossi, P., Gomez Morales, M.A., 2007c. Trichinella zimbabwensis in wild reptiles of Zimbabwe and Mozambique and farmed reptiles of Ethiopia. Vet. Parasitol. 143, 305-310.

Pozio, E., Rinaldi, L., Marucci, G., Musella, V., Galati, F., Cringoli, G., Boireau, P., La Rosa, G., 2009. Hosts and habitats of Trichinella spiralis and Trichinella britovi in Europe. Int. J. Parasitol. 39, 71-79.

Rafter, P., Marucci, G., Brangan, P., Pozio, E., 2005. Rediscovery of Trichinella spiralis in red foxes (Vulpes vulpes) in Ireland after 30 years of oblivion. J. Infect. 50, 6165.

Railliet, A., 1896. Quelques rectifications a la nomenclature des parasites. Recueil de Médicine Véterinaire 3, 157-161.

Rausch, R.L., 1970. Trichinosis in the Arctic. In: Gould, S.E. (Ed.), Trichinosis in man and animals. Charles C. Thomas Publisher, Springfield, IL, pp. 348-373.

Rausch, R.L., Babero, B.B., Rausch, V.R., Schiller, E.L., 1956. Studies on the helminth fauna of Alaska. XXVII. The occurrence of larvae of Trichinella spiralis in Alaskan mammals. J. Parasitol. 42, 259-271.

Reichard, M.V., Torretti, L., Snider, T.A., Garvon, J.M., Marucci, G., Pozio, E., 2008. Trichinella T6 and Trichinella nativa in wolverines (Gulo gulo) from Nunavut, Canada. Parasitol. Res. 103, 657-661.

Rombout, Y.B., Bosch, S., van Der Giessen, J.W., 2001. Detection and identification of eight Trichinella genotypes by reverse line blot hybridization. J. Clin. Microbiol. 39, 642-646.

Rosenthal, B.M., La Rosa, G., Zarlenga, D., Dunams, D., Chunyu, Y., Mingyuan, L., Pozio, E., 2008. Human dispersal of Trichinella spiralis in domesticated pigs. Infect. Genet. Evol. 8, 799-805.

Savage, R.J.G., 1978. Carnivora. In: Maglio, V.J., Cooke, H.B.S. (Eds.), Evolution of African Mammals. Harvard University Press, Cambridge, pp. 249-267.

Soule, C., Guillou, J.P., Dupouy-Camet, J., Vallet, C., Pozio, E., 1993. Differentiation of Trichinella isolates by polymerase chain reaction. Parasitol. Res. 79, 461-465. 
van der Giessen, J.W., Fonville, M., Briels, I., Pozio, E., 2005. Phylogenetic analysis of encapsulated and non-encapsulated Trichinella species by studying the $5 \mathrm{~S}$ rDNA tandemly repeated intergenic region. Vet. Parasitol. 132, 51-55.

Voronov, D.A., Panchin, Y.V., Spiridonov, S.E., 1998. Nematode phylogeny and embryology. Nature 395, 28.

Wang, H., Zhang, Y., Lao, W., Wu, Z., 1995. Restriction fragment length polymorphism (RFLP) analysis of genomic DNA of 5 strains of Trichinella spiralis in China. Chinese Med. Sci. J. 10, 131-135.

Wu, Z., Nagano, I., Takahashi, Y., 1998. The detection of Trichinella with polymerase chain reaction (PCR) primers constructed using sequences of random amplified polymorphic DNA (RAPD) or sequences of complementary DNA encoding excretory-secretory (E-S) glycoproteins. Parasitology 117, 173-183.

Wu, Z., Nagano, I., Pozio, E., Takahashi, Y., 1999. Polymerase chain reaction-restriction fragment length polymorphism (PCR-RFLP) for the identification of Trichinella isolates. Parasitology 118, 211-218.

Wu, Z., Nakada, T., Nagano, I., Takahashi, Y., 2000. DNA fingerprints of Trichinella as revealed by restriction fragment length polymorphism and single-strand conformational polymorphism (RFLP-SSCP). Mol. Cel. Probes 14, 291-297.

Wu, Z., Snabel, V., Pozio, E., Hurnikova, Z., Nareaho, A., Nagano, I., Takahashi, Y. 2007. Genetic relationships among Trichinella pseudospiralis isolates from Australian, Nearctic, and Palearctic regions. Parasitol. Res. 101, 1567-1573.

Zarlenga, D.S., 1998. Molecular aspects of speciation in the genus Trichinella. In: Ortega-Pierres, G., Gamble, R., van Knapen, F., Wakelin, D. (Eds.), Trichinellosis V9. Centro de Investigación y de Estudios Avanzados del IPN, D.F. Mexico, pp. 43-46.
Zarlenga, D.S., Barta, J.R., 1990. DNA analysis in the diagnosis of infection and in the speciation of nematode parasites. Rev. Scient. Tech. Office Int. Epizooties 9, 533554.

Zarlenga, D.S., Dame, J.B., 1992. The identification and characterization of a break within the large subunit ribosomal RNA of Trichinella spiralis: comparison of gap sequences within the genus. Mol. Biochem. Parasitol. 51, 281-290.

Zarlenga, D.S., Aschenbrenner, R.A., Lichtenfels, J.R., 1996. Variations in microsatellite sequences provide evidence for population differences and multiple ribosomal gene repeats within Trichinella pseudospiralis. J. Parasitol. 82, 534538.

Zarlenga, D.S., Chute, M.B., Martin, A., Kapel, C.M., 1999. A multiplex PCR for unequivocal differentiation of all encapsulated and non-encapsulated genotypes of Trichinella. Int. J. Parasitol. 29, 1859-1867.

Zarlenga, D.S., Rosenthal, B.M., La Rosa, G., Pozio, E., Hoberg, E.P., 2006. PostMiocene expansion, colonization, and host switching drove speciation among extant nematodes of the archaic genus Trichinella. Proc. Natl. Acad. Sci. U.S.A. 103, 7354-7359.

Zarlenga, D.S., Rosenthal, B., Hoberg, E., Mitreva, M., 2009. Integrating genomics and phylogenetics in understanding the history of Trichinella species. Vet. Parasitol. $159,210-213$.

Zimmer, I.A., Hunter, S.J., Morgan, C.P., Hunt, K.R., Smith, G.C., Howell, M., Taylor, M.A., 2008. Detection and surveillance for animal trichinellosis in GB. Vet. Parasitol. 151, 233-241. 